\title{
Vital Exhaustion
}

National Cancer Institute

\section{Source}

National Cancer Institute. Vital Exhaustion. NCI Thesaurus. Code C48801.

A condition characterized by excessive fatigue and lack of energy, increasing irritability, and feelings of demoralization. Persons who experience this condition are not at an increased risk for cancer. 